OPEN ACCESS

Edited by:

Susanne Huber,

University of Vienna, Austria

Reviewed by:

Danielle Sulikowski,

Charles Sturt University, Australia Alexander Jensen,

Brigham Young University, USA

${ }^{*}$ Correspondence:

Anna Rotkirch

anna.rotkirch@vaestoliitto.fi

Specialty section:

This article was submitted to Evolutionary Sociology and

Biosociology,

a section of the journal

Frontiers in Sociology

Received: 07 February 2016

Accepted: 06 May 2016

Published: 31 May 2016

Citation:

Tanskanen AO, Danielsbacka M, Jokela M, David-Barrett T and Rotkirch A (2016) Diluted

Competition? Conflicts between Full- and Half-Siblings in Two Adult Generations.

Front. Sociol. 1:6.

doi: 10.3389/fsoc.2016.00006

\section{Diluted Competition? Conflicts between Full- and Half-Siblings in Two Adult Generations}

\author{
Antti O. Tanskanen', Mirkka Danielsbacka ${ }^{2}$, Markus Jokela $^{3}$, Tamas David-Barrett ${ }^{4}$ and \\ Anna Rotkirch ${ }^{2 *}$
}

${ }^{1}$ Social Research, Sociology, University of Turku, Turku, Finland, ${ }^{2}$ Population Research Institute, Väestöliitto - Finnish Family Federation, Helsinki, Finland, ${ }^{3}$ Institute of Behavioural Sciences, Psychology, University of Helsinki, Helsinki, Finland,

${ }^{4}$ Institute for the World Economy, Kiel University, Kiel, Germany

Sibling relations are typically close but ambivalent, including both altruism and competition. Full siblings are often assumed to exhibit more altruism and less competition than half-siblings. However, previous empirical findings indicate that this assumption may not hold for sibling conflicts in contemporary humans. We study self-reported occurrence of sibling conflicts among adults in two generations with nationally representative data from the Generational Transmissions in Finland surveys in 2012. Respondents represent an older generation (born between 1945 and 1950, $n=2,015$ ) and their adult children (born between 1962 and 1993, $n=1,565$ ). Based on kin selection and parent-offspring conflict theory, we expect reports of any conflict to be more likely between full siblings than half-siblings, between maternal half-siblings than paternal half-siblings, and among the younger generation compared to the older generation. Results mostly support our hypotheses. Full siblings were more likely to report conflicts than were maternal and paternal half-siblings in the younger generation. In the older generation, full siblings were more likely to report conflicts with paternal but not maternal half-siblings. The younger generation was also more conflict-prone than the older. Results held when controlling for contact frequency, emotional closeness, unequal parental treatment, and several socioeconomic variables, as well as for within-family effects. Thus, although full siblings are typically closer and have more contact in adulthood than half-siblings do, they also appear to have more conflicts. We suggest that this can be explained by diluted resource competition over parental investment between half-siblings in societies with serial monogamy.

Keywords: sibling conflict, kin selection, parent-offspring conflict, parental investment, sibling competition, sibling relations, stepfamilies, unequal parental treatment

\section{INTRODUCTION}

Sibling competition has been documented across species, and may manifest itself in many forms ranging from minor quarrels to aggression and siblicide (Mock and Parker, 1997; Michalski and Euler, 2008). In humans, milder conflicts and disagreements between siblings are frequent (Pollet and Hoben, 2011), although brothers and sisters are also closely attached which is why this family tie can be characterized as ambivalent (e.g., Cicirelli, 1995; Dunn, 2014). 
Human sibling competition is most severe in childhood, when siblings usually co-reside and parental investment matters most (Salmon and Hehman, 2014), but can appear throughout the adult life course (e.g., Lamb and Sutton-Smith, 1982; White, 2001; Spitze and Trent, 2006). Sibling attachment is created early in life through certain cues, including shared residence and maternal care (Westermarck, 1891; Lieberman et al., 2007) and the quality of this bond in childhood affects adult sibling relations (Pollet and Hoben, 2011). For instance, parental unequal treatment experienced in childhood or adolescence may be remembered for a long time and create more emotional distance between siblings in adulthood (Jensen et al., 2013; Danielsbacka and Tanskanen, 2015).

In early adulthood, siblings often compete over parental resources, such as financial transfers, and help with child care. For instance, contemporary Europeans are less likely to have a child if their own parents are already providing care to the young child of a sibling (Aassve et al., 2012). At later life stages, sibling conflicts occur over, for example, access to shared family resources, caring for aging parents, and inheritance (Cicirelli, 1995).

While studies involving siblings are today abundant within the social sciences, siblinghood is often used to control for family effects rather than as a family tie in its own right (Whiteman et al., 2011; among recent studies, see, e.g., Voorpostel and van der Lippe, 2007; Voorpostel and Blieszner, 2008; Blaauboer et al., 2013; Kolk, 2014; Rotkirch et al., 2014). Research on sibling conflicts among adults are quite rare (but see Stewart et al., 2001; Riggio 2006; Salmon and Hehman, 2015). Here, we are interested in exploring conflict occurrence among adults as an indicator of sibling competition.

It is often hypothesized that full siblings should experience less intense sibling competition compared to half-siblings (Trivers, 1974). For humans, emotional closeness among kin is usually related to increased cooperation and fewer conflicts (Kurland and Gaulin, 2005; Curry et al., 2013). When comparing full- and half-siblings, the former have been found to emotionally closer to each other and to interact more (e.g., Pollet, 2007; Tanskanen and Danielsbacka, 2014). This has led to the assumption that full siblings should also be less conflict-prone when compared to half-siblings (e.g., Schlomer et al., 2011; Salmon and Hehman, 2015). Nevertheless, recent evidence, intriguingly, indicates that this may not be always the case. Two recent studies among US college students (Salmon and Hehman, 2015) and British adolescents (Tanskanen et al., 2016) found full siblings to experience more conflicts than half-siblings. Sibling conflict occurrence has not, however, previously been studied among adults using large and representative data, which is the purpose of our study here.

Evolutionary perspectives on sibling competition rely on two fundamental biological theories: kin selection theory (Hamilton, 1964; Hughes, 1988) and parent-offspring conflict theory (Trivers, 1974; Schlomer et al., 2011). Kin selection theory focuses on the effect of genetic relatedness on altruistic behavior, while parent-offspring conflict theory focuses on the effect of parental investment on parent and offspring relations and, by extension, on sibling competition for limited parental resources. Both theories predict behavior to evolve in order to maximize inclusive fitness, or the proportion of an individual's genes passed on to subsequent generations.
First, kin selection theory predicts that individuals are more likely to provide help and to invest resources in genetically closer kin compared to more distantly related kin and to non-kin (Hamilton, 1964). Consequently, also conflicts between family members can be assumed to decrease as genetic relatedness is higher (Schlomer et al., 2011, 509). Hughes (1988) (pp. 35-56) applied and expanded kin selection theory to humans, showing that both reciprocal exchange and fitness-increasing cooperation are more likely to appear among full siblings than half-siblings. However, his results highlighted the complexity of the effects of sibling relatedness, so that results were not uniformly in favor of full siblings even for simple cooperation models. Hughes (1988) (pp. 42-47) further specified the conditions of nepotistic sharing in human groups in relation to both the degree of relatedness and the reproductive potential of the individuals involved. Reproductive potential is measured as the likelihood to have offspring in the future and, thus, directly related to age. Hughes predicted that altruistic help should be more likely provided from older kin generations to younger generations than among peers, and that peer competition should diminish once individuals are no longer reproducing and their own reproductive potential is 0 .

Second, parent-offspring conflict theory states that a parent's evolutionarily optimal level of investment in any given offspring is determined by the relative benefits of investing in that offspring compared to investing in other current and future offspring (Trivers, 1974). Offspring are, thus, expected to compete for limited parental resources (Salmon and Malcolm, 2011). Theoretically, this competition between offspring can be so extreme that it reduces or even negates the prosocial influence of kin altruism on behavior (West et al., 2002). The intensity of sibling competition will depend on many factors, including the amount of resources available and how equally parents are inclined to divide them among offspring. Resource scarcity as well as abundance can both be assumed to increase sibling competition (Pollet and Hoben, 2011). Perceived unfairness from parents is known to increase resentment and competition among siblings (e.g., Danielsbacka and Tanskanen, 2015). Furthermore, individual characteristics, such as age, health, and gender contribute to tensions among siblings, usually so that similarity and proximity feeds competition and promote differentiation (e.g., Feinberg and Hetherington, 2000; Salmon and Hehman, 2015). Thus, being of the same sex can intensify competition over similar types of resources (in addition, two brothers tend to have more conflicts than two sisters; Brody et al., 1985). Also the numbers of siblings, their birth order, and birth intervals are known to influence sibling relations (e.g., Salmon, 1999; Black et al., 2005; Nitsch et al., 2013) - the smaller the age difference, the more conflicts over shared parental resources, albeit large age differences may reduce relationship closeness (Pollet and Hoben, 2011).

The extent of parent-offspring conflict will also depend on the investment each of the individual's original parents provides in case half-siblings are born. If one parent produces additional offspring with a new partner, the other parent and existing offspring can both be affected, but the magnitude of this cost or benefit depends on the mating and parenting system. Lessells and Parker (1999) modeled costs of additional offspring to parents and siblings for a hypothetical species with uniparental care. 
They found that in some cases, the offspring's optimal parental investment may be independent of whether a full or half-sibling is born. These authors, therefore, stress that it is not average sibling relatedness per se, but the costs that one of the parents causes the other parent in terms of inclusive fitness, that shapes parent-offspring conflict and, by extension, sibling competition.

In humans, both mothers and fathers usually invest in offspring. Half-siblings are typically born either within polygamous marriages (polygamy), as a result of death and remarriage (strict monogamy) as in preindustrial Europe, or as a result of divorce and remarriage (serial monogamy) as in most contemporary countries (e.g., Anderson, 2011; Pettay et al., 2013). Under conditions of serial monogamy, both of the original parents and their kin networks are usually alive and present in the child's life. Such blended families are increasingly common in contemporary Europe, where children usually reside with their mothers if parents have separated, but their biological fathers continue to keep in contact with and provide support for them (Amato, 2010). This creates a crucial difference between full and half-siblings in terms of the kin network they can expect most investment from. Full siblings have exactly the same biological kin network, while half-siblings share only half of their biological kin network. For the overlapping part of the kin network (the shared parent), half-siblings can be predicted to compete more intensely than full siblings do, due to their lower relatedness. This hypothesis has been tested and confirmed for parent-offspring conflict in both birds and humans (Schlomer et al., 2011). By contrast, however, for the non-overlapping part of their kin networks, half-siblings can be predicted to exhibit no or very little competition toward each other. We call this the diluted sibling competition hypothesis (Tanskanen et al., 2016; see also Michalski and Euler, 2008).

Finally, studies on sibling relations should separate between maternal and paternal half-siblings. Previous research shows that although these siblings share a similar level of genetic relatedness, they often differ from each other with regard to relationship quality (e.g., Pollet, 2007; Tanskanen and Danielsbacka, 2014). The main proximate reason is probably co-residence in childhood. In polygynous societies, half-siblings tend to be related through their father; while in contemporary Western societies, children usually co-reside with their mother after divorce, so that maternal siblings on average interact more than paternal siblings do. Also the effect of paternity uncertainty may weaken the bond between paternal siblings, making individuals unconsciously prefer their genetically more certain and maternal kin ties over less certain and paternal kin ties (Laham et al., 2005).

To sum up, the theoretical approaches outlined above provide five main assumptions for the effects of genetic relatedness on sibling relations in contemporary Western societies:

1. Based on inclusive fitness theory, full siblings are more likely to exhibit greater emotional closeness and be more in contact with each other compared to half-siblings.

2. Based on the diluted sibling competition hypothesis, full siblings are more likely to compete with each other than halfsiblings are, since the sources of parental investment are fully overlapping among full siblings but only partly overlapping among half-siblings.
3. Based on parent-offspring conflict theory, competition for the overlapping part of the kin network (i.e., the shared parent and his or her kin) should be stronger for half-siblings than for full siblings.

4. Also based on parent-offspring conflict theory, similarity in life stage and the resources being competed for should increase both emotional closeness and competition. Such similarities include sibling age, gender, and co-residence.

5. Based on inclusive fitness theory, individual reproductive potential correlates with sibling competition, which is, therefore, expected to decline with age.

This study touches upon four of these five predictions (excluding number 3). We have two main research questions: Are full siblings more likely to report conflicts compared to maternal and to paternal half-siblings? Is the amount of conflict higher in the younger adult generation compared to their parents' generation? We expect

(i) full siblings to report more conflicts than half-siblings, and also maternal half-siblings to report more conflicts than paternal half-siblings

(ii) the younger adult generation to report more sibling conflicts than the older generation.

\section{DATA AND METHODS}

We use data from the Generational Transmissions in Finland (Gentrans) project. The aim of Gentrans is to gather longitudinal information on two generations: the Finnish "baby boomer" generation born immediately after World War II, between 1945 and $1950(\mathrm{M}=1947, \mathrm{SD}=1.67)$ (the older generation), and their adult children, born between 1962 and $1993(\mathrm{M}=1976, \mathrm{SD}=5.6)$ (the younger generation). The two family generations represent different cohorts and historical experiences. Fertility was quite high (total fertility rates above 3 ) and divorces uncommon in Finland in the 1940s and 1950s, when respondents from the older generation were children. In the 1970s-1990s, when the younger generation grew up, total fertility rates were below two and the number of parents divorcing every year had more than doubled compared to the post-war decades (Statistics Finland, 2012). At the study time, the younger adults were closer in time to their childhood, when they probably had more intense competition over parental resources and also more conflicts with their siblings. They were also more likely to have at least one parent alive, compared to the older generation whose parents have usually already both died (Statistics Finland, 2012). Respondents from the younger generation were, furthermore, in the middle of their childbearing and working career years and, thus, had "more at stake," compared to the older generation who were already retired or close to retirement age.

The first wave of the Gentrans surveys was gathered in 2007. Ethical permission for this and subsequent surveys were obtained by the Ethical board of Statistics Finland (decision 2.6.2006). This study uses the second wave, which was collected in 2012 by Statistics Finland via regular mail. The surveys of the older 
and younger generations were gathered separately. During the data collection in 2012, respondents from the older generation were around 65 years old (between 62 and 67) and those from the younger generation mostly in their 20s, 30s, and 40s (mean 36 , min $19, \max 50$ ). The older generation's survey included altogether 2,278 respondents (response rate 65\%), and the younger generation's survey included 1,753 respondents (response rate 50\%) (Danielsbacka et al., 2013).

In the Gentrans surveys, respondents were asked whether they and their sibling have the same biological mother and father, same mother only, or same father only. If respondents reported having the same mother and father as the sibling, the relationship was coded as a full sibling relationship. For cases with only the same mother or only the same father, the relationship was coded as a half-sibling relationship. Only respondents with at least one full or half-sibling were included in the analysis (older generation: $n=2,015$; younger generation: $n=1,565)$. Maternal half-siblings and paternal half-siblings were also separated into different categories. We will assume that maternal half-siblings have been living together in the same household for a longer time. In the last decades in Finland, at least $80 \%$ or more of children who do not live with both biological parents were registered as staying with their mothers (Statistics Finland, 2012).

The dependent variable measures sibling conflicts, which the respondents reported separately for up to four of the respondents' oldest siblings. In the questionnaires, the respondents were asked "Have you had conflicts with your sibling? How often?" The question did not define any specific time span for the occurrence of these conflicts. We interpret the responses to measure respondent's overall susceptibility to conflicts in his/her relationship with the specific sibling rather than an exact amount of conflicts in a specific time frame. Respondents reported conflicts with each of their siblings on a scale of $1=$ never to $4=$ often $($ mean $=1.64$, $\mathrm{SD}=0.75$ for the older generation; mean $=1.9, \mathrm{SD}=0.76$ for the younger generation).

For the analysis, we dichotomized the sibling conflict variable as $0=$ never, $1=$ at least sometimes. $50.1 \%$ of the older generation's and $66.7 \%$ of the younger generation's respondents reported having had sibling conflicts. The dependent variables were dichotomized because these were not normally distributed in either survey and, thus, analyses with continuous variables could not have been performed properly. Sensitivity analyses conducted with continuous variables produced similar results (not shown) to analyses with the dichotomized variables, so that the loss of information appears to have been very small. For the purposes of the analyses, the data were reshaped into a long format, so that observations represent the siblings of the original respondents. In the case of the older generation, this resulted in a total of 5,102 observations; and in the case of the younger generation this resulted in 2,801 observations from the data.

In the case of contact frequencies, respondents were asked via a five-point scale (from $0=$ never to $4=$ several times a week) to report how often they have had contact with their siblings either personally, by phone or by internet during the last 12 months. Contact frequencies were gathered separately for four of the respondents' oldest siblings. Emotional closeness was measured by asking respondents how close they feel to their siblings using a five-point scale (from $0=$ very distant, to $4=$ very close). Also the ratings of emotional closeness were asked separately for the respondents' four oldest siblings.

Regarding parental equal treatment, respondents were asked whether their mother, their father, neither parent, or both parents have treated all siblings equally. For the analysis, we coded the unequal treatment variable as $0=$ both treated equally, $1=$ mother treated equally, father not, 2 = father treated equally, mother not, and 3 = both treated unequally. With the exception of the respondent's birth year, the number of siblings, the age difference between siblings, sibling's year of birth, contact frequencies and reported emotional closeness between siblings, all independent variables were categorical and were transformed into dummy variables.

Since sibling conflict may vary by life stage and age, we first studied the two surveyed generations separately. We then merged the data and compared older and younger generations to each other. We ran three regression models. In the first step, we control for respondents' year of birth and in the second step for emotional closeness and frequency of sibling contacts. These may correlate negatively with conflict occurrence, so that those who are closer to their siblings prefer to see each other more often (Salmon and Hehman, 2014) but also positively, since a higher contact frequency allows for more conflicts. In the third model, we further control for respondent age, gender, sibling age difference, sibling birth order, number of siblings, and perceptions of parental unequal treatment, and geographical distance, as well as educational level and wealth, for reasons described in the section "Introduction" (see Table 1 for descriptive statistics).

We used multilevel logistic regression analysis in which the multiple sibling conflicts reported by the respondents are grouped within respondents. This method takes into account the non-independence of sibling conflicts reported by the same respondent. Regression coefficients were expressed as odds ratios (ORs) for which an OR above 1 indicates a positive association between the independent variable and the outcome, while ORs under 1 indicate a negative association.

\section{RESULTS}

The descriptive results (Table 1) show that older generation respondents have an average of two and younger generation respondents 1.6 siblings. Around 5\% of respondents in the older generation had maternal and $2 \%$ had paternal half-siblings. In the younger generation, these numbers were $8 \%$ and $6 \%$, respectively.

In both generations, full siblings tend to be emotionally closer with one another than half-siblings (younger generation: full sibling $=$ ref., maternal half-siblings: $\beta=-0.59, \mathrm{SE}=0.13$, $p<0.001$, paternal half-sibling: $\beta .=-1.87, \mathrm{SE}=0.15$, $p<0.001, n=2,795$; older generation: full sibling $=$ ref., maternal half-sibling: $\beta=-0.73, \mathrm{SE}=0.12, p<0.001$, paternal half-sibling: $\beta=-0.55$, SE $=0.20, p=0.005, n=5,045)$. Full siblings also have more contacts with each other compared to 
TABLE 1 | Descriptive statistics ( $n$ and $\% / m e a n)$.

\begin{tabular}{|c|c|c|c|c|c|c|}
\hline & \multicolumn{3}{|c|}{ Younger generation } & \multicolumn{3}{|c|}{ Older generation } \\
\hline & $n$ & $\% /$ mean & SD & $n$ & $\% /$ mean & SD \\
\hline \multicolumn{7}{|l|}{ Sibling relationship (\%) } \\
\hline Full sibling & 2,425 & 86.6 & & 4,749 & 93.1 & \\
\hline Maternal half-sibling & 209 & 7.5 & & 258 & 5.1 & \\
\hline Paternal half-sibling & 167 & 6.0 & & 95 & 1.9 & \\
\hline Respondent's birth year (mean) & 1,565 & 1976 & 5.60 & 2,015 & 1947 & 1.67 \\
\hline \multicolumn{7}{|l|}{ Respondent's education (\%) } \\
\hline Primary or lower secondary level & 52 & 3.4 & & 643 & 32.6 & \\
\hline Upper secondary level & 662 & 42.7 & & 996 & 50.5 & \\
\hline Lower degree level tertiary education & 424 & 27.3 & & 128 & 6.5 & \\
\hline Higher degree level tertiary education or doctorate education & 414 & 26.7 & & 206 & 10.4 & \\
\hline \multicolumn{7}{|l|}{ Respondent's perceived financial condition (\%) } \\
\hline Low income & 461 & 29.7 & & 899 & 45.0 & \\
\hline Middle income & 766 & 49.3 & & 751 & 37.6 & \\
\hline Comfortably off or wealthy & 326 & 21.0 & & 350 & 17.5 & \\
\hline Respondent's number of siblings (mean) & 1,556 & 2.0 & 1.52 & 1,958 & 3.7 & 2.41 \\
\hline \multicolumn{7}{|l|}{ Respondent's birth order (\%) } \\
\hline First born & 624 & 40.3 & & 584 & 29.7 & \\
\hline Later born & 923 & 59.7 & & 1,384 & 70.3 & \\
\hline \multicolumn{7}{|l|}{ Sex of respondent and sibling (\%) } \\
\hline Female and female & 896 & 32.1 & & 1,546 & 30.6 & \\
\hline Female and male & 1,409 & 50.4 & & 2,451 & 48.5 & \\
\hline Male and male & 489 & 17.5 & & 1,060 & 21.0 & \\
\hline Sibling's birth year (mean) & 2,755 & 1976 & 6.52 & 4,961 & 1947 & 7.31 \\
\hline Age difference between respondent and sibling (mean) & 2,755 & 6.2 & 4.55 & 4,961 & 5.7 & 4.26 \\
\hline \multicolumn{7}{|l|}{ Geographical distance between respondent and siblings (\%) } \\
\hline Less than $1 \mathrm{~km}$ & 53 & 1.9 & & 121 & 2.5 & \\
\hline $1-5 \mathrm{~km}$ & 192 & 6.9 & & 429 & 8.8 & \\
\hline $5-25 \mathrm{~km}$ & 736 & 26.6 & & 938 & 19.2 & \\
\hline $25-100$ km & 528 & 19.1 & & 1,037 & 21.2 & \\
\hline $100-500 \mathrm{~km}$ & 939 & 33.9 & & 1,801 & 36.9 & \\
\hline More than 500 km & 320 & 11.6 & & 558 & 11.4 & \\
\hline Emotional closeness (mean) & 2,795 & 2.8 & 0.99 & 5,045 & 2.7 & 0.91 \\
\hline Contact frequencies (mean) & 2.796 & 2.1 & 1.09 & 5.012 & 1.7 & 1.01 \\
\hline \multicolumn{7}{|l|}{ Did parents treat all siblings equally (\%) } \\
\hline Both treated equally & 1,091 & 73.1 & & 1,503 & 79.2 & \\
\hline Mother treated equally, father not & 95 & 6.4 & & 145 & 7.6 & \\
\hline Father treated equally, mother not & 114 & 7.6 & & 111 & 5.9 & \\
\hline Both treated unequally & 193 & 12.9 & & 140 & 7.4 & \\
\hline
\end{tabular}

Basic data: respondent's birth year, education, financial condition, number of siblings, birth order, and parental treatment; long format data: sibling relationship, sex of respondent and sibling, sibling's birth year, age difference, geographical distance, emotional closeness, and contact frequencies.

half-siblings (younger generation: full sibling $=$ ref., maternal half-sibling: $\beta=-1.00, \mathrm{SE}=0.13, p<0.001$, paternal half-sibling: $\beta=-2.14, \mathrm{SE}=0.16, p<0.001, n=2,796$; older generation: full sibling $=$ ref., maternal half-sibling: $\beta=-0.76, \mathrm{SE}=0.12$, $p<0.001$, paternal half-sibling: $\beta=-0.71, \mathrm{SE}=0.20, p<0.001$, $n=5,012)$.

\section{Conflicts in the Younger Generation}

Conflicts in the younger generation were more likely to be reported among full siblings than among either maternal or paternal half-siblings (Table 2). Compared to full siblings (ref., $\mathrm{OR}=1.00$ ), the ORs were 0.19 and 0.04 for maternal and paternal half-siblings, respectively, in the first model with no other covariates than respondent's birth year. The results are affected to only a very slight degree by including emotional closeness and contact frequency into the regression. In the fully adjusted model, the difference between full siblings and maternal half-siblings is smaller but still significant, while the difference to paternal half-siblings is not much affected (see Figure 1). In the maximally adjusted model the difference between maternal and paternal half-siblings is statistically significant (maternal half-siblings (ref): $\mathrm{OR}=1.00$; paternal half-siblings: $\mathrm{OR}=0.15, p<0.001 ; n=2,540)$.

To adjust for all stable differences between different respondents, we conducted a within-respondent analysis using 
TABLE 2 | Younger generation: associations of sibling characteristics with sibling conflicts (odds ratios).

\begin{tabular}{|c|c|c|c|c|c|c|c|c|c|c|c|c|c|c|c|}
\hline & \multicolumn{5}{|c|}{ Model 1} & \multicolumn{5}{|c|}{ Model 2} & \multicolumn{5}{|c|}{ Model 3} \\
\hline & \multicolumn{5}{|c|}{$95 \% \mathrm{Cl}$} & \multicolumn{5}{|c|}{$95 \% \mathrm{Cl}$} & \multicolumn{5}{|c|}{$95 \% \mathrm{Cl}$} \\
\hline & OR & SE & $p$ & Lower & Upper & OR & SE & $p$ & Lower & Upper & OR & SE & $p$ & Lower & Upper \\
\hline \multicolumn{16}{|l|}{ Sibling relationship } \\
\hline Full sibling (ref) & 1.00 & & & & & 1.00 & & & & & 1.00 & & & & \\
\hline Maternal half-sibling & 0.19 & 0.06 & $<0.001$ & 0.10 & 0.35 & 0.22 & 0.07 & $<0.001$ & 0.12 & 0.41 & 0.47 & 0.18 & 0.043 & 0.22 & 0.98 \\
\hline Paternal half-sibling & 0.04 & 0.01 & $<0.001$ & 0.02 & 0.08 & 0.04 & 0.02 & $<0.001$ & 0.02 & 0.09 & 0.07 & 0.03 & $<0.001$ & 0.03 & 0.17 \\
\hline Respondent's birth year & 1.00 & 0.02 & 0.977 & 0.97 & 1.03 & 1.00 & 0.02 & 0.797 & 0.96 & 1.03 & 1.05 & 0.03 & 0.051 & 1.00 & 1.10 \\
\hline \multicolumn{16}{|l|}{ Respondent's education } \\
\hline Primary or lower secondary level (ref) & & & & & & & & & & & 1.00 & & & & \\
\hline Upper secondary level & & & & & & & & & & & 1.02 & 0.66 & 0.979 & 0.29 & 3.62 \\
\hline Lower degree level tertiary education & & & & & & & & & & & 1.13 & 0.76 & 0.855 & 0.30 & 4.20 \\
\hline $\begin{array}{l}\text { Higher degree level tertiary } \\
\text { education or doctorate education }\end{array}$ & & & & & & & & & & & 0.55 & 0.38 & 0.384 & 0.15 & 2.10 \\
\hline \multicolumn{16}{|l|}{$\begin{array}{l}\text { Respondent's perceived financial } \\
\text { condition }\end{array}$} \\
\hline Low income (ref) & & & & & & & & & & & 1.00 & & & & \\
\hline Middle income & & & & & & & & & & & 1.39 & 0.38 & 0.222 & 0.82 & 2.37 \\
\hline Comfortably off or wealthy & & & & & & & & & & & 1.44 & 0.50 & 0.294 & 0.73 & 2.83 \\
\hline Respondent's number of siblings & & & & & & & & & & & 0.79 & 0.06 & 0.001 & 0.69 & 0.90 \\
\hline \multicolumn{16}{|l|}{ Respondent's birth order } \\
\hline First born (ref) & & & & & & & & & & & 1.00 & & & & \\
\hline Later born & & & & & & & & & & & 0.73 & 0.21 & 0.281 & 0.42 & 1.29 \\
\hline \multicolumn{16}{|l|}{ Sex of respondent and sibling } \\
\hline Female and female (ref) & & & & & & & & & & & 1.00 & & & & \\
\hline Female and male & & & & & & & & & & & 0.30 & 0.06 & $<0.001$ & 0.20 & 0.46 \\
\hline Male and male & & & & & & & & & & & 0.73 & 0.21 & 0.281 & 0.42 & 1.30 \\
\hline Sibling's birth year & & & & & & & & & & & 0.999 & 0.02 & 0.940 & 0.97 & 1.03 \\
\hline $\begin{array}{l}\text { Age difference between respondent } \\
\text { and sibling }\end{array}$ & & & & & & & & & & & 0.87 & 0.02 & $<0.001$ & 0.83 & 0.91 \\
\hline \multicolumn{16}{|l|}{$\begin{array}{l}\text { Geographical distance between } \\
\text { respondent and sibling }\end{array}$} \\
\hline Less than $1 \mathrm{~km}$ (ref) & & & & & & & & & & & 1.00 & & & & \\
\hline $1-5 \mathrm{~km}$ & & & & & & & & & & & 0.70 & 0.52 & 0.626 & 0.16 & 2.97 \\
\hline $5-25 \mathrm{~km}$ & & & & & & & & & & & 0.55 & 0.38 & 0.379 & 0.14 & 2.10 \\
\hline $25-100 \mathrm{~km}$ & & & & & & & & & & & 0.45 & 0.31 & 0.254 & 0.12 & 1.77 \\
\hline $100-500 \mathrm{~km}$ & & & & & & & & & & & 0.42 & 0.29 & 0.209 & 0.11 & 1.63 \\
\hline More than 500 km & & & & & & & & & & & 0.59 & 0.29 & 0.462 & 0.10 & 1.63 \\
\hline Emotional closeness between siblings & & & & & & 0.56 & 0.06 & $<0.001$ & 0.46 & 0.69 & 0.55 & 0.07 & $<0.001$ & 0.43 & 0.71 \\
\hline Contact frequencies between siblings & & & & & & 1.92 & 0.19 & $<0.001$ & 1.58 & 2.34 & 1.47 & 0.17 & 0.001 & 1.17 & 1.86 \\
\hline \multicolumn{16}{|l|}{ Did parents treat all siblings equally } \\
\hline Both treated equally (ref) & & & & & & & & & & & 1.00 & & & & \\
\hline Mother treated equally, father not & & & & & & & & & & & 2.45 & 1.16 & 0.058 & 0.97 & 6.22 \\
\hline Father treated equally, mother not & & & & & & & & & & & 1.50 & 0.62 & 0.329 & 0.66 & 3.39 \\
\hline Both treated unequally & & & & & & & & & & & 3.06 & 1.10 & 0.002 & 1.51 & 6.20 \\
\hline n (number of observations) & & & 2,801 & & & & & 2,790 & & & & & 2,540 & & \\
\hline$n$ (number of respondents) & & & 1,555 & & & & & 1,553 & & & & & 1.411 & & \\
\hline
\end{tabular}

Model 1, univariate association, adjusted for age.

Model 2, adjusted for age, contacts, and emotional closeness.

Model 3, multivariate association, maximally adjusted.

fixed-effect regressions that included 240 respondents $(n=675$ sibling observations) who had variance in the outcome variable. ORs for the within-respondent analysis (full siblings (ref): $\mathrm{OR}=1.00$; maternal half-siblings: $\mathrm{OR}=0.18, p<0.001$; paternal half-siblings: $\mathrm{OR}=0.09, p<0.001)$ were similar to those for the total analysis.

As Table 2 also shows, the odds of sibling conflict decrease with higher emotional closeness but increase with higher contact 


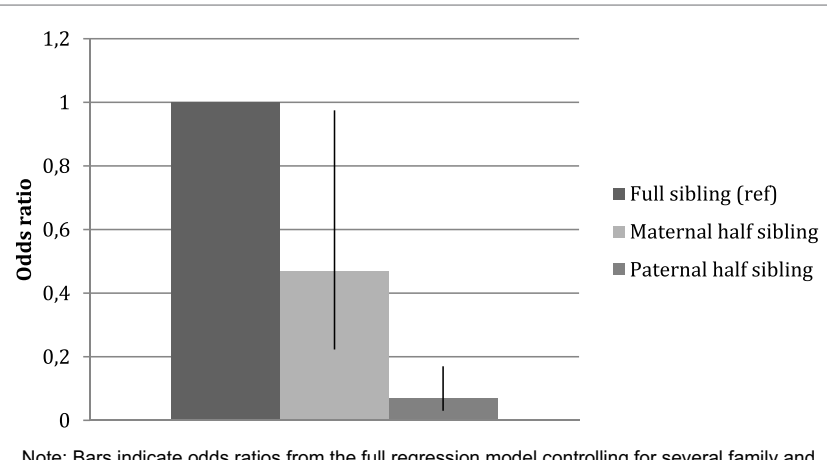

Note: Bars indicate odds ratios from the full regression model controlling for several family and socioeconomic variables; error bars are $95 \%$ confidence intervals.

FIGURE 1 | Younger generation: associations of sibling relationships with sibling conflicts (maximally adjusted).

frequency. In the third and fully adjusted model, the age of respondents has a marginally significant effect increasing the odds of reporting conflicts. Having more siblings and a larger age difference was associated with decreased odds of conflicts. Female-female constellations were more likely to report conflicts than were female-male constellations. As expected, respondents who thought that both of their parents had not treated all siblings equally had greater odds to have conflicts compared to respondents who thought parents had treated all siblings equally.

\section{Conflicts in the Older Generation}

Next, we conducted the same analyses for the parents of the younger generation. Respondents from the older generation have greater odds of having conflicts with their full than with their half-siblings (Table 3). However, this difference was statistically significant only in the case of paternal half-siblings. The odds for having conflicts with paternal half-siblings are similar in minimally and maximally adjusted regression models, and they are also similar to those for paternal half-siblings among the younger generation (see Table 2). In the third model, which includes all studied variables in the same regression, the difference in the likelihood to have conflicts between full and maternal half-siblings has almost disappeared (see Figure 2). In the maximally adjusted model the difference between maternal and paternal half-siblings is statistically significant (maternal half-siblings (ref): $\mathrm{OR}=1.00$; paternal half-siblings: $\mathrm{OR}=0.05, p=0.001 ; n=4,263$ ).

The corresponding within-respondent analysis included 439 respondents ( $n=1,402$ sibling observations) with all types of siblings. The trend was the same for within-family analysis (full siblings (ref): $\mathrm{OR}=1.00$; maternal half-siblings: $\mathrm{OR}=0.52$, $p=0.087$; paternal half-siblings: $\mathrm{OR}=0.12, p=0.010$ ) as in the main analysis.

As for the younger generation, higher emotional closeness among the older generation was associated with decreased odds of having conflicts and higher contact frequency with increased odds. However, in the case of contact frequencies, the difference was no longer statistically significant after all other variables were controlled for in the third model. Sister-sister pairs had greater probability for conflicts than did other sibling constellations.
Having more siblings and having a larger age difference were both associated with decreased conflict proneness. Perceived unequal treatment of parents was related to higher odds of reporting conflicts compared to those who reported equal treatment. Unequal treatment from the father or from both parents gave the strongest associations with reported conflicts. Longer geographical distance between siblings was associated with decreased probability of conflicts. Finally, comfortably off or wealthy respondents, were both less likely to report conflicts than those with low income.

\section{A Comparison between Generations}

Finally, we combined both data sets and compared the probability of conflicts between the two studied family generations, in order to test our second hypothesis. Using the older generation as the reference category, the younger generation had significantly greater odds of reporting sibling conflicts. The results were similar in minimally $(\mathrm{OR}=1.98, \mathrm{SE}=0.13$, $p<0.001, n=8,008)$ and maximally $(\mathrm{OR}=1.85, \mathrm{SE}=0.38$, $p=0.003, n=6,801)$ adjusted models.

\section{DISCUSSION}

Sibling relations are usually life-long, important and complex, yet relatively few studies have investigated the conflictual side of sibling relations in adulthood using large data. We studied how the likelihood of sibling conflict is associated with genetic relatedness in two adult family generations from contemporary Finland. Based on inclusive fitness theory and parent-offspring conflict theory as applied to human societies with serial monogamy, our hypotheses were that full siblings would be more likely to report any conflict compared to half-siblings, and that among half-siblings, the maternal siblings would report more conflict compared to paternal siblings. We also hypothesized that the younger generation would be more likely to report having any conflicts with a sibling compared to the older generation. The hypotheses were largely confirmed. In the case of the younger generation, who were mostly in their 20s-40s at the time of the study, full siblings had more conflicts than half-siblings and maternal half-siblings more than paternal ones. In the case of the older generation, whose respondents were 62-67 years old, conflicts were more likely to be reported with full siblings compared to paternal half-siblings, while the difference between full siblings and maternal half-siblings was not statistically significant. Maternal half-siblings were more likely to have conflicts than paternal half-siblings. Notably, all these results held also after controlling for emotional closeness, contact frequencies, unequal parental treatment, and other demographic and socioeconomic family variables as well as for within-family effects.

As expected, the older adult generation reported lower likelihood of having any conflict with a sibling. The two generations studied here differed from each other also in other respects, partly due to them representing different historical experiences, with the older "baby boomer" generation being born immediately after World War II. The older generation had fewer half-siblings overall, and especially less paternal half-siblings, and probalby more often had acquired any half-siblings due to remarriage following widowhood. 
TABLE 3 | Older generation: associations of sibling characteristics with sibling conflicts (odds ratios).

\begin{tabular}{|c|c|c|c|c|c|c|c|c|c|c|c|c|c|c|c|}
\hline & \multicolumn{5}{|c|}{ Model 1} & \multicolumn{5}{|c|}{ Model 2} & \multicolumn{5}{|c|}{ Model 3} \\
\hline & \multicolumn{5}{|c|}{$95 \% \mathrm{Cl}$} & \multicolumn{5}{|c|}{$95 \% \mathrm{Cl}$} & \multicolumn{5}{|c|}{$95 \% \mathrm{Cl}$} \\
\hline & OR & SE & $p$ & Lower & Upper & OR & SE & $p$ & Lower & Upper & OR & SE & $p$ & Lower & Upper \\
\hline \multicolumn{16}{|l|}{ Sibling relationship } \\
\hline Full sibling (ref) & 1.00 & & & & & 1.00 & & & & & 1.00 & & & & \\
\hline Maternal half-sibling & 0.69 & 0.21 & 0.230 & 0.37 & 1.27 & 0.53 & 0.18 & 0.065 & 0.27 & 1.04 & 0.90 & 0.40 & 0.817 & 0.38 & 2.14 \\
\hline Paternal half-sibling & 0.06 & 0.04 & $<0.001$ & 0.02 & 0.21 & 0.04 & 0.03 & $<0.001$ & 0.01 & 0.15 & 0.04 & 0.04 & $<0.001$ & 0.01 & 0.25 \\
\hline Respondent's birth year & 1.10 & 0.07 & 0.126 & 0.97 & 1.24 & 1.13 & 0.07 & 0.73 & 0.99 & 1.28 & 1.14 & 0.09 & 0.104 & 0.97 & 1.33 \\
\hline \multicolumn{16}{|l|}{ Respondent's education } \\
\hline Primary or lower secondary level (ref) & & & & & & & & & & & 1.00 & & & & \\
\hline Upper secondary level & & & & & & & & & & & 1.63 & 0.49 & 0.103 & 0.91 & 2.93 \\
\hline Lower degree level tertiary education & & & & & & & & & & & 2.62 & 1.45 & 0.082 & 0.88 & 7.75 \\
\hline $\begin{array}{l}\text { Higher degree level tertiary } \\
\text { education or doctorate education }\end{array}$ & & & & & & & & & & & 1.84 & 0.91 & 0.218 & 0.70 & 4.84 \\
\hline \multicolumn{16}{|l|}{$\begin{array}{l}\text { Respondent's perceived financial } \\
\text { condition }\end{array}$} \\
\hline Low income (ref) & & & & & & & & & & & 1.00 & & & & \\
\hline Middle income & & & & & & & & & & & 0.72 & 0.21 & 0.254 & 0.41 & 1.27 \\
\hline Comfortably off or wealthy & & & & & & & & & & & 0.28 & 0.11 & 0.001 & 0.13 & 0.61 \\
\hline Respondent's number of siblings & & & & & & & & & & & 0.84 & 0.05 & 0.001 & 0.75 & 0.93 \\
\hline \multicolumn{16}{|l|}{ Respondent's birth order } \\
\hline First born (ref) & & & & & & & & & & & 1.00 & & & & \\
\hline Later born & & & & & & & & & & & 0.92 & 0.29 & 0.779 & 0.49 & 1.69 \\
\hline \multicolumn{16}{|l|}{ Sex of respondent and sibling } \\
\hline Female and female (ref) & & & & & & & & & & & 1.00 & & & & \\
\hline Female and male & & & & & & & & & & & 0.40 & 0.07 & $<0.001$ & 0.28 & 0.57 \\
\hline Male and male & & & & & & & & & & & 0.54 & 0.13 & 0.012 & 0.33 & 0.87 \\
\hline Sibling's birth year & & & & & & & & & & & 0.998 & 0.02 & 0.898 & 0.97 & 1.02 \\
\hline $\begin{array}{l}\text { Age difference between respondent } \\
\text { and sibling }\end{array}$ & & & & & & & & & & & 0.94 & 0.02 & $<0.001$ & 0.91 & 0.97 \\
\hline \multicolumn{16}{|l|}{$\begin{array}{l}\text { Geographical distance between } \\
\text { respondent and sibling }\end{array}$} \\
\hline Less than $1 \mathrm{~km}$ (ref) & & & & & & & & & & & 1.00 & & & & \\
\hline $1-5 \mathrm{~km}$ & & & & & & & & & & & 0.76 & 0.38 & 0.577 & 0.29 & 2.01 \\
\hline $5-25 \mathrm{~km}$ & & & & & & & & & & & 0.47 & 0.23 & 0.122 & 0.18 & 1.22 \\
\hline $25-100$ km & & & & & & & & & & & 0.28 & 0.14 & 0.009 & 0.11 & 0.73 \\
\hline $100-500$ km & & & & & & & & & & & 0.26 & 0.13 & 0.006 & 0.10 & 0.60 \\
\hline More than 500 km & & & & & & & & & & & 0.21 & 0.11 & 0.003 & 0.08 & 0.58 \\
\hline Emotional closeness between siblings & & & & & & 0.26 & 0.03 & $<0.001$ & 0.21 & 0.32 & 0.24 & 0.03 & $<0.001$ & 0.19 & 0.31 \\
\hline Contact frequencies between siblings & & & & & & 1.46 & 0.12 & $<0.001$ & 1.24 & 1.71 & 1.08 & 0.11 & 0.449 & 0.89 & 1.31 \\
\hline \multicolumn{16}{|l|}{ Did parents treat all siblings equally } \\
\hline Both treated equally (ref) & & & & & & & & & & & 1.00 & & & & \\
\hline Mother treated equally, father not & & & & & & & & & & & 14.35 & 7.02 & $<0.001$ & 5.50 & 37.46 \\
\hline Father treated equally, mother not & & & & & & & & & & & 2.58 & 1.37 & 0.073 & 0.91 & 7.28 \\
\hline Both treated unequally & & & & & & & & & & & 4.25 & 2.07 & 0.003 & 1.64 & 11.03 \\
\hline n (number of observations) & & & 5,102 & & & & & 4,992 & & & & & 4,263 & & \\
\hline$n$ (number of respondents) & & & 1,977 & & & & & 1,962 & & & & & 1,697 & & \\
\hline
\end{tabular}

Model 1, univariate association, adjusted for age.

Model 2, adjusted for age, contacts, and emotional closeness.

Model 3, multivariate association, maximally adjusted.

Our results are in line with a series of studies, which suggest that although full siblings are often very close and supportive, they are also more conflict-prone than half-siblings. For instance, a previous study of young children measured sibling negativity (conflict and aggression) within a sample of 192 families and found it to be higher among full siblings compared to half-siblings (Deater-Deckard et al., 2002). Research by Salmon and Hehman (2015) investigated sibling conflicts with a sample 


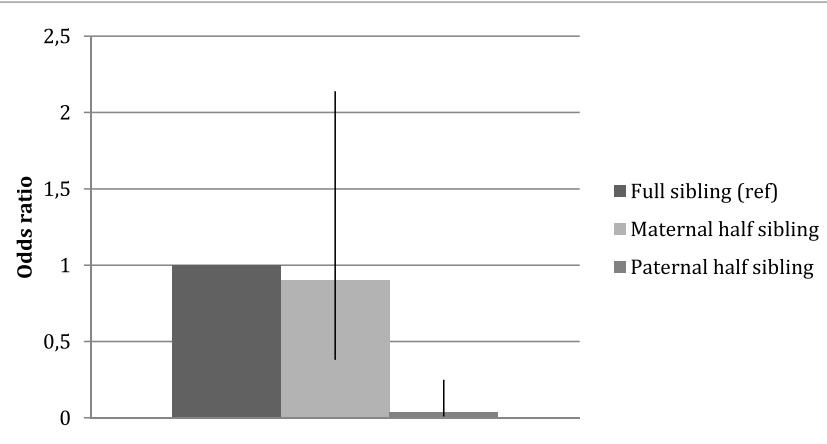

Note: Bars indicate odds ratios from the full regression model controlling for several family and socioeconomic variables; error bars are $95 \%$ confidence intervals.

FIGURE 2 | Older generation: associations of sibling relationships with sibling conflicts (maximally adjusted).

of 345 US college students and Tanskanen et al. (2016) studied over 7,500 young adolescents from the UK, both studies finding more conflicts among full siblings compared to half-siblings.

This body of evidence, expanded to young adulthood and older adulthood by the present study, suggests that siblings do not confirm to general predictions about family ties and genetic relatedness (Trivers, 1974; Schlomer et al., 2010). Higher relatedness does correlate with a higher quality of the sibling relationship (as measured by, e.g., emotional closeness and frequency of contacts). It can also correlate with lower levels of parent-offspring competition for a particular shared parent, as studied among birds (e.g., Briskie et al., 1994) and humans (Schlomer et al., 2010). However, full siblings appear to compete more overall. We suggest that this may be explained by the diluted sibling competition hypothesis. This hypothesis takes into account the often overlooked fact that full siblings compete over the same two parents, and their kin networks. Half-siblings have only one shared parent and, thus, the option to receive investment from their other biological parent, diluting the focus of parentoffspring competition among them. When both parents continue parental investment after divorce, as is usually the case in serially monogamous contemporary Western societies, one may, thus, predict lower levels of competition and conflicts between half siblings than full siblings (Tanskanen et al., 2016). One would still predict, however, fewer conflicts between monozygotic and dizygotic twins, as found in Smith (2007), since among these full siblings only the degree of relatedness varies but not the parental network. The diluted competition hypotheses may explain the lack of difference between maternal half and full siblings found in the older generation in the present study, although we could not test this with available data. If a mother remarried and had more children after the death of her first spouse during the war, her children did not have access to the same diluted kinship network as children of divorced parents do. Theoretical criticism of Trivers (1974) original article on parent-offspring and sibling competition has similarly stressed that sibling competition depends on the ensuing family constellations and need not always be sharper among half than full siblings (Lessells and Parker, 1999), although this line of thought has not been applied to humans.
Resources, measured here as economic situation and level of education, often diminished the likelihood of sibling conflict. Older generation respondents who were comfortably off had a significantly decreased likelihood to have conflicts with siblings compared to low-income respondents, in line with previous research showing higher family tensions in lower income groups (Pollet and Hoben, 2011). The likelihood of conflict decreased with increasing geographical distance among the older generation. Other studies have shown that siblings prefer to live close to each other, especially if they follow convergent life course patterns (Blaauboer et al., 2013; Kolk, 2014).

Emotional closeness toward a particular sibling was related to decreased likelihood of conflicts. Having more siblings and having large age differences decreased the likelihood of reporting conflicts in adulthood. This was expected regarding age differences, but somewhat of a surprise concerning the number of siblings, since having more children should intensify competition for parental resources. Some earlier studies also found fewer conflicts (Stewart et al., 2001) and happier memories (if not better relationships as adults) (Riggio 2006) in larger sibships, suggesting that having more options with whom to interact may reduce conflicts. We further found that brother-sister pairs were also significantly less likely to report conflicts than were sister-sister pairs in both generations. For the older generation, brothers were also less likely to have conflicts than sisters were. This gender effect contradicts our assumption and former results (Brody et al., 1985; CampioneBarr and Smetana, 2010) showing that boys and opposite-sex siblings have more conflicts in childhood and in adolescence, while sisters are often represented as the most harmonious type of siblings. We conducted a separate analysis to explore if the higher conflict proneness among sisters was due to their higher contact frequency, but found no interaction between these variables in either family generation; therefore, this finding awaits replication and explanation.

Among the advantages of the study is that our data are large and nationally representative, and that we controlled for within person-effects as well as many confounding sociological variables. We expanded the topic of sibling conflicts to include younger and older adults, finding partly similar if weaker effects with age. A limitation of our data is that we did not have exact information on co-residence of siblings during childhood. However, because we know that in Finland children typically stay with their mothers if parents separate, we can assume that most maternal half-siblings have grown up together.

Another limitation is that the data are cross-sectional and we could use only a general assessment of conflict occurrence, which did not distinguish between types of conflicts or the time when they occurred.

The results could be different if one measured severe conflicts, such as direct aggression and fall outs. A study of UK children found that half-siblings were more likely to be injured in the household compared to full siblings, which can be interpreted as an expression of more extreme sibling competition among halfsiblings (Tanskanen et al., 2015). It is also important to remember that not all conflicts will reflect sibling competition over parental resources. However, the strong effect of unequal parental 
treatment on the likelihood of reporting any sibling conflict does indicate that conflicts are related to parental resources and attention (cf. Brody et al., 1992a,b).

In sum, we found evidence for higher conflicts proneness between full siblings and maternal and, especially, paternal half-siblings, suggesting that sibling ties do not always confirm to general predictions about family ties and genetic relatedness. Our findings may be explained by the diluted sibling competition hypothesis. This hypothesis is indirectly present in an early suggestion by Hughes (1988) (pp. 132) who proposed to study how step-paternal treatment of a child varies when the child receives investment from its biological father, thus alluding to the complex interactions of blended family networks. The diluted competition hypothesis has to our knowledge not been properly quantified or tested, for which one would need data with measurements of both sibling relations and the non-residing parent's investments. Future studies could also expand the diluted sibling competition hypothesis to include all the possible forms of kin investment in a child - by grandparents, aunts,

\section{REFERENCES}

Aassve, A., Meroni, E., and Pronzato, C. (2012). Grandparenting and childbearing in the extended family. Eur. J. Popul. 28, 499-518. doi:10.1007/ s10680-012-9273-2

Amato, P. R. (2010). Research on divorce: continuing trends and new developments. J. Marriage Fam. 72, 650-666. doi:10.1111/j.1741-3737.2010. 00723.x

Anderson, K. G. (2011). "Stepparenting, divorce, and investment in children," in The Oxford Handbook on Evolutionary Family Psychology, eds C.Salmon and T. K.Shackelford (New York: Oxford University Press), 97-112.

Blaauboer, M., Stromgren, M., and Stjernstrom, O. (2013). Life course preferences, sibling ties, and the geographical dispersion of sibling networks. Popul. Space Place 19, 594-609. doi:10.1002/psp.1742

Black, S. E., Devereux, P. J., and Salvanes, K. G. (2005). The more the merrier? The effect of family size and birth order on children's education. Q. J. Econ. 120, 669-700. doi:10.1162/0033553053970179

Briskie, J. V., Naugler, C. T., and Leech, S. M. (1994). Begging intensity of nestling birds varies with sibling relatedness. Proc. Biol. Sci. 258, 73-78. doi:10.1098/ rspb.1994.0144

Brody, G. H., Stoneman, Z., MacKinnon, C. E., and MacKinnon, R. (1985). Role relationships and behavior between preschool-aged and school-aged sibling pairs. Dev. Psychol. 21, 124. doi:10.1037/0012-1649.21.1.124

Brody, G. H., Stoneman, Z., and McCoy, J. K. (1992a). Associations of maternal and paternal direct and differential behavior with sibling relationships: contemporaneous and longitudinal analyses. Child Dev. 63, 82-92. doi: $10.2307 / 1130903$

Brody, G. H., Stoneman, Z., McCoy, J. K., and Forehand, R. (1992b). Contemporaneous and longitudinal associations of sibling conflict with family relationship assessments and family discussions about sibling problems. Child Dev. 63, 391-400. doi:10.2307/1131487

Campione-Barr, N., and Smetana, J. G. (2010). "Who said you could wear my sweater?" Adolescent siblings' conflicts and association with relationship quality. Child Dev. 81, 464-471. doi:10.1111/j.1467-8624.2009.01407.x

Cicirelli, V. G. (1995). Sibling Relationships Across the Life Span. New York: Plenum Press.

Curry, O., Roberts, S. G. B., and Dunbar, R. I. M. (2013). Altruism in social networks: evidence for a "kinship premium." Br. J. Psychol. 104, 283-295. doi:10.1111/j.2044-8295.2012.02119.x

Danielsbacka, M., and Tanskanen, A. O. (2015). The association between unequal parental treatment and the sibling relationship in Finland: the difference between full and half siblings. Evol. Psychol. 13, 492-510.

Danielsbacka, M., Tanskanen, A. O., Hämäläinen, H., Pelkonen, I., HaavioMannila, E., Rotkirch, A., et al. (2013). Sukupolvien vuorovaikutus. Auttaminen uncles, and so on - that become larger in blended compared to nuclear families.

\section{AUTHOR CONTRIBUTIONS}

AT, MD, and AR designed the study and acquired data; AT and MJ conducted the statistical analyses; all authors interpreted the results; and AR and AT wrote the article.

\section{ACKNOWLEDGMENTS}

The authors thank Statistics Finland for collecting the data and Venla Berg and the referees for insightful comments.

\section{FUNDING}

The authors are grateful to the Academy of Finland for funding the data collection and research (project nr 250620 for AR, AT and MD; 266898 for MJ and TD-B).

ja yhteydenpito suurten ikäluokkien ja heidän lastensa elämässä. [InterGenerational Relations: Helping and Interaction in the Life of Finnish Baby Boomers and Their Adult Children]. Helsinki: Finnish Family Federation.

Deater-Deckard, K., Dunn, J., and Lussier, G. (2002). Sibling relationships and social-emotional adjustment in different family contexts. Soc. Dev. 11, 571-590. doi:10.1111/1467-9507.00216

Dunn, J. (2014). "Sibling relationshoíps across the life-span," in Sibling Matters: A Psychoanalytic, Developmental, and Systemic Approach, eds D.Hindle and S.Sherwin-White (London: Karnac Books), 69-81.

Feinberg, M. E., and Hetherington, E. M. (2000). Sibling differentiation in adolescence: implications for behavioral genetic theory. Child Dev. 71, 1512-1524. doi:10.1111/1467-8624.00243

Hamilton, W. D. (1964). The genetical evolution of social behaviour I and II. J. Theor. Biol. 7, 1-52. doi:10.1016/0022-5193(64)90039-6

Hughes, A. L. (1988). Evolution and Human Kinship. Oxford: Oxford University Press.

Jensen, A. C., Whiteman, S. D., Fingerman, K. L., and Birditt, K. S. (2013). "Life still isn't fair": parental differential treatment of young adult siblings. J. Marriage Fam. 75, 438-452. doi:10.1111/jomf.12002

Kolk, M. (2014). A life course analysis of geographical distance to siblings, parents and grandparents in Sweden. Stockholm Res. Rep. Demography 13, $1-25$.

Kurland, J. A., and Gaulin, S. J. C. (2005). "Cooperation and conflict among kin,” in The Handbook of Evolutionary Psychology, ed. D. M.Buss (Hoboken, NJ: Wiley), 447-482.

Laham, S. M., Gonsalkorale, K., and von Hippel, W. (2005). Darwinian grandparenting: preferential investment in more certain kin. Pers. Soc. Psychol. Bull. 31, 63-72. doi:10.1177/0146167204271318

Lamb, M. E., and Sutton-Smith, B. (1982). Sibling Relationships: Their Nature and Significance across the Lifespan. London, New York: Psychology Press.

Lessells, C. M., and Parker, G. A. (1999). Parent-offspring conflict: the fullsib-half-sib fallacy. Proc. Biol. Sci. 266, 1637-1643. doi:10.1098/rspb.1999. 0826

Lieberman, D., Tooby, J., and Cosmides, L. (2007). The architecture of human kin detection. Nature 445, 727-731. doi:10.1038/nature05510

Michalski, R. L., and Euler, H. A. (2008). "Evolutionary perspectives on sibling relationships," in Family Relationships: An Evolutionary Perspective, eds C.Salmon and T. K.Shackelford (New York: Oxford University Press), 185-204.

Mock, D. W., and Parker, G. A. (1997). The Evolution of Sibling Rivalry. Oxford: Oxford University Press

Nitsch, A., Faurie, C., and Lummaa, V. (2013). Are elder siblings helpers or competitors? Antagonistic fitness effects of sibling interactions in humans. Proc. Biol. Sci. 280, 20122313. doi:10.1098/rspb.2012.2313 
Pettay, J. E., Rotkirch, A., Courtiol, A., Jokela, M., and Lummaa, V. (2013). Effects of remarriage after widowhood on long-term fitness in a monogamous historical human population. Behav. Ecol. Sociobiol. 68, 135-143. doi:10.1007/ s00265-013-1630-6

Pollet, T. V. (2007). Genetic relatedness and sibling relationship characteristics in a modern society. Evol. Human Behav. 28, 176-185. doi:10.1016/j. evolhumbehav.2006.10.001

Pollet, T. V., and Hoben, A. D. (2011). "An evolutionary perspective on siblings: rivals and resources," in The Oxford Handbook on Evolutionary Family Psychology, eds C.Salmon and T. K.Shackelford (New York: Oxford University Press), 128-148.

Riggio, H. R. (2006). Structural features of sibling dyads and attitudes toward sibling relationships in young adulthood. J. Fam. Issues 27, 1233-1254.

Rotkirch, A., Lyons, M., David-Barrett, T., and Jokela, M. (2014). Gratitude for help among friends and siblings. Evol. Psychol. 12, 673-686. doi:10.1177/ 147470491401200401

Salmon, C. A. (1999). On the impact of sex and birth order on contact with kin. Hum. Nat. 10, 183-197. doi:10.1007/s12110-999-1014-9

Salmon, C. A., and Hehman, J. A. (2014). "The evolutionary psychology of sibling conflict and siblicide," in The Evolution of Violence, eds T. K.Shackelford and R. D.Hansen (New York: Springer), 137-157.

Salmon, C. A., and Hehman, J. A. (2015). Evolutionary perspectives on the nature of sibling conflict: the impact of sex, relatedness, and co-residence. Evol. Psychol. Sci. 1, 123-129. doi:10.1007/s40806-015-0013-9

Salmon, C. A., and Malcolm, J. (2011). "Parent-offspring conflict," in The Oxford Handbook on Evolutionary Family Psychology, eds C. Salmon and T. K.Shackelford (New York: Oxford University Press), 83-96.

Schlomer, G., Ellis, B., and Garber, J. (2010). Mother-child conflict and sibling relatedness: a test of hypotheses from parent-offspring conflict theory. J. Res. Adolesc. 20, 287-306. doi:10.1111/j.1532-7795.2010.00641.x

Schlomer, G. L., Del Giudice, M., and Ellis, B. J. (2011). Parent-offspring conflict theory: an evolutionary framework for understanding conflict within human families. Psychol. Rev. 118, 496-521. doi:10.1037/a0024043

Smith, M. A. M. (2007). Similarities and Differences Between Adolescent Monozygotic and Dyzygotic Twins' Quality of the Sibling Relationship. UT Electronic Theses and Dissertations. The University of Texas at Austin. Proquest [Dissertations] and Theses Database (UMI No. 3284734). Available at: http://hdl.handle. net/2152/3396

Spitze, G., and Trent, K. (2006). Gender differences in adult sibling relations in twochild families. J. Marriage Fam. 68, 977-992. doi:10.1111/j.1741-3737.2006. 00308.x

Statistics Finland. (2012). Families. Helsinki: Statistics Finland.
Stewart, R., Kozak, A. , Tingley, L., Goddard, J. Blake, E. and Cassel, W. (2001). Adult sibling relationships: Validation of a typology. Pers. Relat. 8, 299-324.

Tanskanen, A. O., and Danielsbacka, M. (2014). Genetic relatedness predicts contact frequencies with siblings, nieces and nephews: results from the generational transmissions in Finland surveys. Pers. Individ. Dif. 50, 5-11. doi:10.1016/j. paid.2014.04.034

Tanskanen, A. O., Danielsbacka, M., Jokela, M., and Rotkirch, A. (2016). Sibling conflicts in full- and half-sibling households in the UK. J. Biosoc. Sci. 48. doi:10.1017/S0021932016000043

Tanskanen, A. O., Danielsbacka, M., and Rotkirch, A. (2015). More injuries in half sibling than full sibling households in the UK. J. Individ. Differ. 36, 177-182. doi:10.1027/1614-0001/a000171

Trivers, R. L. (1974). Parent-offspring conflict. Am. Zool. 14, 249-264. doi:10.1093/ icb/14.1.249

Voorpostel, M., and Blieszner, R. (2008). Intergenerational solidarity and support between adult siblings. J. Marriage Fam. 70, 157-167. doi:10.1111/ j.1741-3737.2007.00468.x

Voorpostel, M., and van der Lippe, T. (2007). Support between siblings and between friends: two worlds apart? J. Marriage Fam. 69, 1271-1282. doi:10.1111/j.1741-3737.2007.00446.x

West, S., Pen, I., and Griffin, A. (2002). Cooperation and competition between relatives. Science 296, 72-75. doi:10.1126/science.1065507

Westermarck, E. A. (1891/1921). The History of Human Marriage, 5th Edn. London: MacMillan.

White, L. K. (2001). Sibling relationships over the life course: a panel analysis. J. Marriage Fam. 63, 555-568. doi:10.1111/j.1741-3737.2001.00555.x

Whiteman, S. D., McHale, S. M., and Soli, A. (2011). Theoretical perspectives on sibling relationships. J. Fam. Theory Rev. 3, 124-139. doi:10.1111/j.1756-2589. 2011.00087.x

Conflict of Interest Statement: The authors declare that this research was conducted in the absence of any commercial or financial relationships that could be construed as a potential conflict of interest.

Copyright (C) 2016 Tanskanen, Danielsbacka, Jokela, David-Barrett and Rotkirch. This is an open-access article distributed under the terms of the Creative Commons Attribution License (CC BY). The use, distribution or reproduction in other forums is permitted, provided the original author(s) or licensor are credited and that the original publication in this journal is cited, in accordance with accepted academic practice. No use, distribution or reproduction is permitted which does not comply with these terms. 